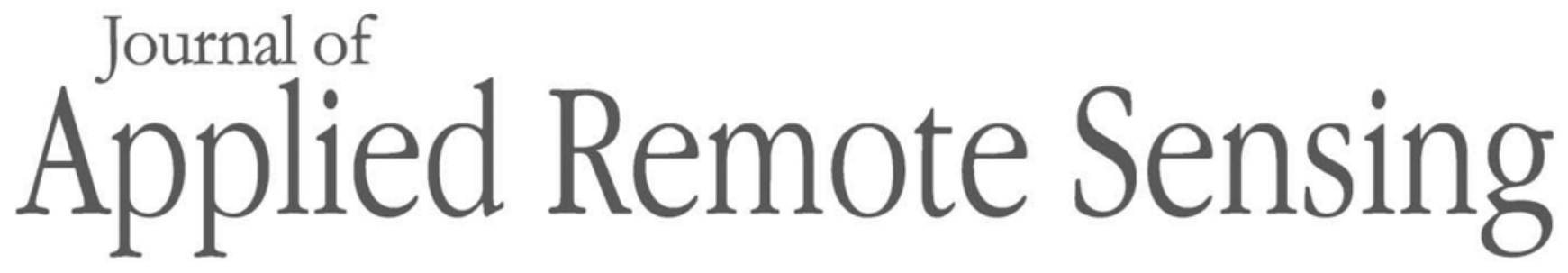

RemoteSensing.SPIEDigitalLibrary.org

\title{
Anthropogenic subsidence along railway and road infrastructures in Northern Italy highlighted by Cosmo-SkyMed satellite data
}

\author{
Marco Polcari \\ Marco Moro \\ Vito Romaniello \\ Salvatore Stramondo
}




\title{
Anthropogenic subsidence along railway and road infrastructures in Northern Italy highlighted by Cosmo-SkyMed satellite data
}

\author{
Marco Polcari,* Marco Moro, Vito Romaniello, and Salvatore Stramondo
}

Istituto Nazionale di Geofisica e Vulcanologia, Rome, Italy

\begin{abstract}
We use X-band Cosmo-SkyMed InSAR data to highlight several subsidence phenomena resting on some railway and road infrastructures in Lombardia region, Northern Italy, mainly induced by anthropogenic activities. We show eight case studies, namely "Como," Erba, Oggiono, Valmadrera, Olginate, Verduggio, Melzo, and San Giuliano M., where we detect local subsidence effects affecting several railway and highway lines with deformation rates of about $5 \mathrm{~mm} /$ year. The geological features of this part of Italy and the large presence of industrial areas in the surrounding of Milano, Lecco, and Como cities lead to such phenomena. The stability and security of the nested road and railway network could be affected by these surface deformation fields. To guarantee the safety of people, continuous maintenance of the condition of railways and roads together with the monitoring of the conditions of the lands on which they rest on should be done. (C) The Authors. Published by SPIE under a Creative Commons Attribution 4.0 Unported License. Distribution or reproduction of this work in whole or in part requires full attribution of the original publication, including its DOI. [DOI: 10.1117/1.JRS.13.024515]
\end{abstract}

Keywords: synthetic aperture radar interferometry; Northern Italy; subsidence; railway and road infrastructure; anthrophogenic-induced effects.

Paper 190023 received Jan. 11, 2019; accepted for publication Apr. 11, 2019; published online May 13, 2019.

\section{Introduction}

Since the beginning of the 90s, synthetic aperture radar interferometry (InSAR) data have been used for supporting the analysis of several natural phenomena, such as earthquakes, volcanoes, landslides, and so on. ${ }^{1-3}$ Indeed, based on the phase of the backscattered signals, the InSAR data are able to constrain along the satellite line-of-sight (LoS) any crustal deformation allowing to have real information about a ground displacement field. The increasing number of space missions together with the rapid development of SAR sensors and algorithms of data processing, such as persistent scatterers (PS), ${ }^{4}$ small baseline subsets (SBAS), ${ }^{5}$ interferometric point target analysis (IPTA) ${ }^{6}$ and SqueeSAR, ${ }^{7}$ made it possible to improve quality and resolution of the acquired images and then the InSAR products providing deformation measurements in the order of millimeters. ${ }^{8}$ This allowed to reduce the scale of the observed phenomena giving the opportunity to exploit InSAR data for studying urban areas, ${ }^{9,10}$ civil infrastructures, and even single buildings. ${ }^{11}$ Nowadays, InSAR products are applied in the analysis of deformations occurring on dams, ${ }^{12,13}$ bridges,${ }^{14}$ railways ${ }^{15}$ or roads,${ }^{16}$ which are often affected by thermal effects, inducing a periodic quasi-sinusoidal seasonal-dependent deformation. ${ }^{17}$ However, sometimes they are subject to greater stress fields produced by other phenomena, such as natural- or anthropogenic-induced subsidence that can be dangerous for the stability of the structure itself even causing damages and collapses. ${ }^{18,19}$

In this work, we exploited X-band Cosmo-SkyMed (CSK) InSAR data to detect some anthropogenic-induced local subsidence phenomena resting on several railways and highways in Lombardia region, Northern Italy, in the proximity of Milano city and between Lecco and Como cities. This sector of Italy has already been investigated in several studies, revealing some subsidence phenomena in the surrounding of Po Plain. ${ }^{20-23}$

*Address all correspondence to Marco Polcari, E-mail: marco.polcari@ingv.it 
Lombardia is one of the most industrialized areas of Italy with the large presence of many metallurgical plants and crude oil refineries together with active and/or ceased quarries, several industries in the mechanical, chemical and textile sectors, reclaimed sites, waste treatment sites, and landfills. This intense anthropogenic-industrial activity produces several subsidence effects due to excessive groundwater exploitation, ${ }^{24}$ extraction of hydrocarbon ${ }^{25}$ and hydrogeological reclamations ${ }^{26}$ especially in proximity of lakes such as Lake Como, Lake Annone, and Lake Pusiano. At the same time, Lombardia has a very widespread railway and road network with many intraregional connections to Milano or toward Switzerland or neighboring Veneto and Piemonte regions. Unfortunately, on January 2018 a train accident occurred near the Pioltello station, eastern Milano, which caused three casualties and more than 40 injured. In addition, some criticalities have been observed also on the road infrastructure as, for example, the overpass collapsing close to Annone Brianza town (Lecco) on October 2016.

Every day, more than 700,000 commuters move along the entire region then, in order to guarantee the safety of the people, continuous maintenance of the condition of railways and roads together with the monitoring of the conditions of the lands on which they rest on is needed.

\section{Geological Settings}

The study area is located in the western sector of the Po Plain, a fluvial basin elongated in an east-west direction between the mountain ranges of the Alps and the Apennines. The Po Plain foredeep is characterized by the convergence of two chains beneath the Po River floodplain: the western southern Alps and the northern Apennines. ${ }^{27,28}$ The western southern Alps are related to the subduction of Europe underneath the Adriatic plate, whereas the northern Apennines are generated along the "westward" subduction of the Adriatic lithosphere below the Tyrrhenian basin. Several authors described the regional geological setting and the Quaternary evolution of the area. ${ }^{29-31}$ The study area is characterized by three different sectors represented by Mesozoic carbonatic reliefs, Oligo-Miocene conglomerates of the Southern-Alpine molasses, and the Como Quaternary basin. The Mesozoic carbonatic sequence is constituted by wellbedded Liassic siliceous limestones; molasse sediments are constituted by coarse polygenic conglomerates and sandstones belonging to the Lombardian Gonfolite Group ("Como Fm.," Upper Oligocene). ${ }^{32}$ The study area was affected during the Quaternary by glacial periods, which shaped the landscape morphology with erosional and depositional glaciers activity. Several glacial expansions involved the Central Alps starting from the Middle Pleistocene and generating ice tongues up to $2 \mathrm{~km}$ thick, in the piedmont belt and the Northern Po Plain. ${ }^{33}$ During the last glacial maximum, 22 to $20 \mathrm{kyr} \mathrm{BP}{ }^{34}$ frontal moraines expanded south of Como; in the subsequent early late glacial retreat, a lake formed where glacier deposits, constituted by clay and silt containing clasts and pebbles of varying lithology, sedimented. ${ }^{35}$ The progressive lake level lowering developed a lacustrine-palustrine environment in the Como sedimentary basin during the Dryas II-Allerød. During the Holocene, the shallow water basin occupying the Como plain was progressively filled up by the alluvial deposits of the Cosia Stream. ${ }^{36}$ The anthropogenic activity produced fires and deforestation increasing the sediment load of the local streams and consequently their depositional capacity. An increase of the thickness of the alluvial sand and gravel deposits took place during the last $3.5 \mathrm{kyr}$, larger than that deposited during the previous $10 \mathrm{kyr}$; slope and fan deposits contributed to the infilling of the basin.

\section{InSAR Data}

The satellite data used in this work consist of two datasets of X-band SAR data acquired in Stripmap mode by the CSK missions of the Italian Space Agency (ASI) from 2014 to 2018. Because of the small wavelength of $3.1 \mathrm{~cm}$, the X-band data allow retrieving high-resolution images $(\sim 3 \mathrm{~m})$ preserving details useful in the study of civil infrastructures. The first dataset, namely in the following "Como-Lecco dataset," consists of 45 single-look complex CSK images acquired along descending orbit from January 2014 to November 2016 and covering the area surrounding Lake Como. On the other hand, the second dataset, hereinafter "Milano dataset," is centered on Milano city, i.e., more southern, and consists of 21 SLC CSK images along 
ascending orbit spanning from August 2015 to January 2018. Both datasets were multilooked by factors of $5 \times 5$ retrieving a pixel posting of about $10 \mathrm{~m}$ along both range and azimuth direction. The InSAR processing was performed by multibaseline IPTA approach developed in the framework of GAMMA software. ${ }^{6}$ We retrieved a redundant interferogram network for both datasets by setting the threshold of the maximum perpendicular and temporal baseline to $500 \mathrm{~m}$ and 600 days for the Como-Lecco dataset and to $1000 \mathrm{~m}$ and 1000 days for the Milano dataset. Such different choices, returning, respectively, 319 and 175 interferograms for Como-Lecco and Milano dataset, have been due to the different number of SAR images. In order to remove the topography from the interferometric phase, we used the 30-m digital elevation model provided by the Shuttle Radar Topography Mission (SRTM), oversampled by a factor of 3 to obtain approximately the same size of the SAR images. Goldstein filtering ${ }^{37}$ was also applied while the phase unwrapping step was performed by the minimum cost flow (MCF) algorithm. ${ }^{38}$

(a)

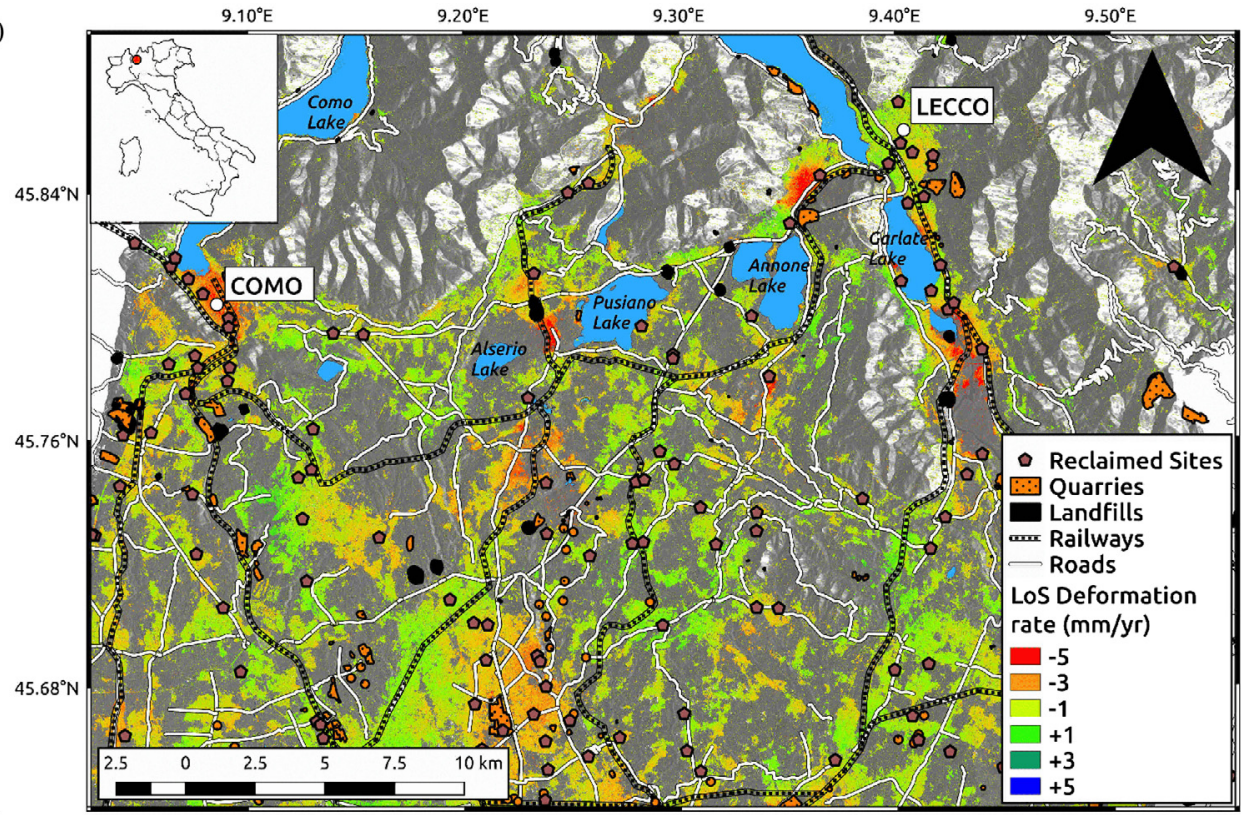

(b)

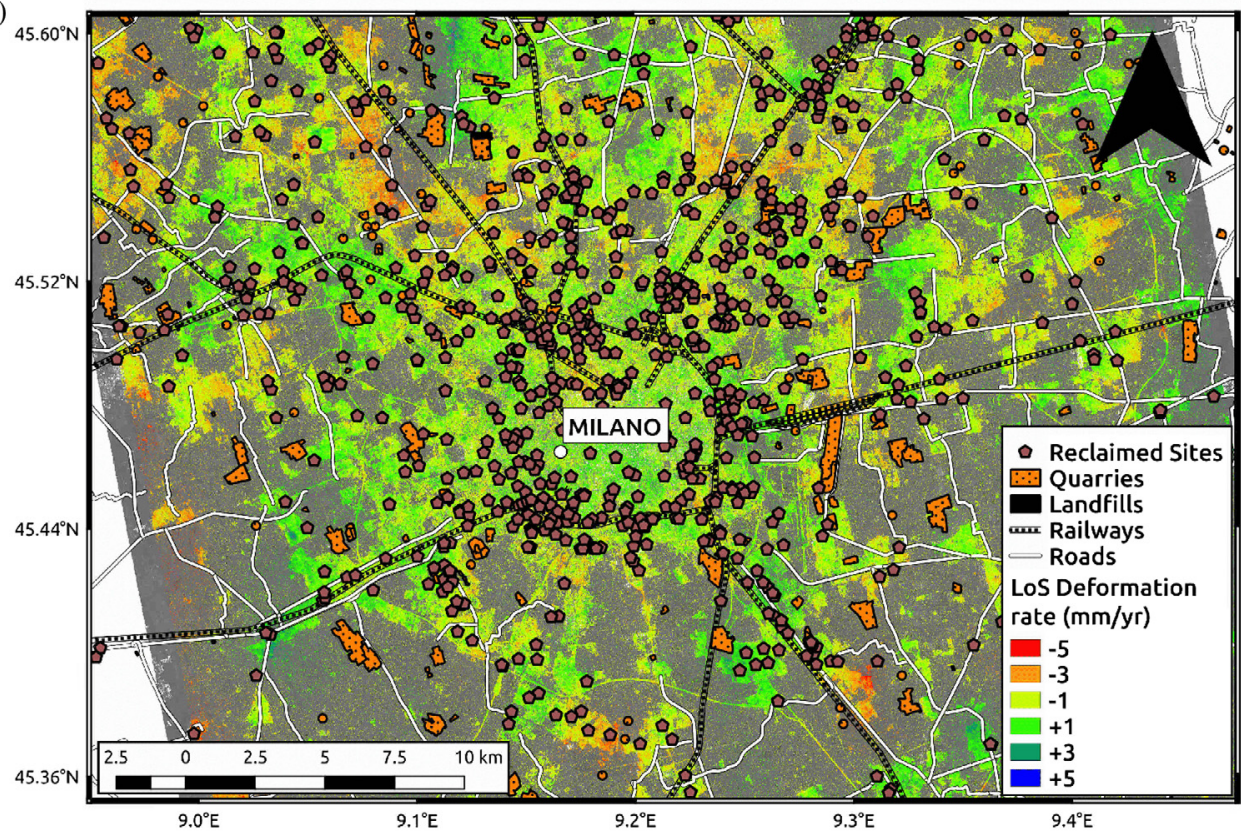

Fig. 1 InSAR deformation velocity maps retrieved by the X-band CSK data. (a) The Como-Lecco dataset and (b) the Milano dataset. 


\section{Results}

The outcomes of the CSK InSAR analysis are shown in Figs. 1 and 2. Deformation rate and time series were estimated along the satellite LoS. Because of the satellite geometry of view, deformation fields induced by subsidence phenomena are well constrained being mainly characterized by vertical displacements.

As clearly observable both in the overview of Fig. 1 and in the focus of Fig. 2, several localized subsidence effects resting on railway and road infrastructures are ongoing in Lombardia region. In particular, in the upper CSK frame, we identified six areas affected by subsidence,

(a)

(c)

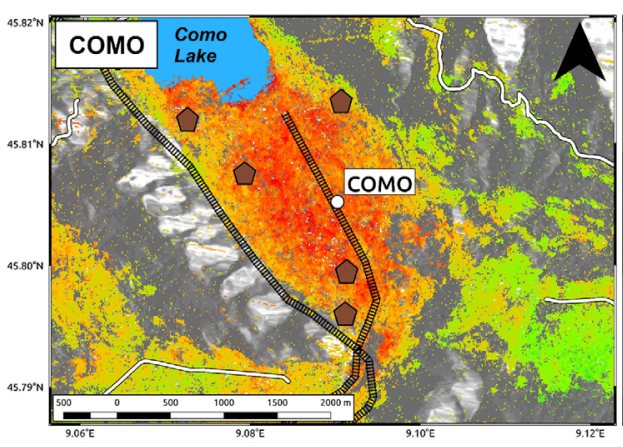

(e)

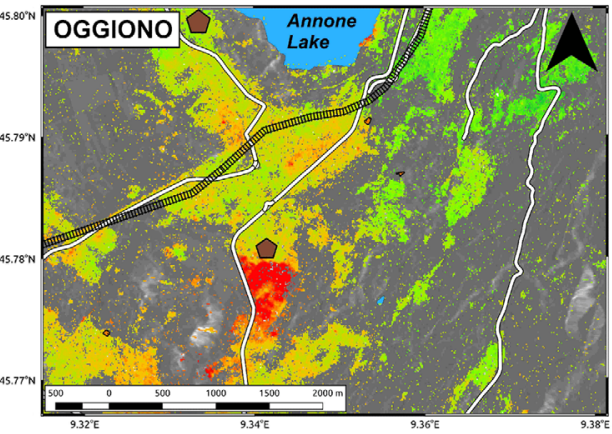

(g)
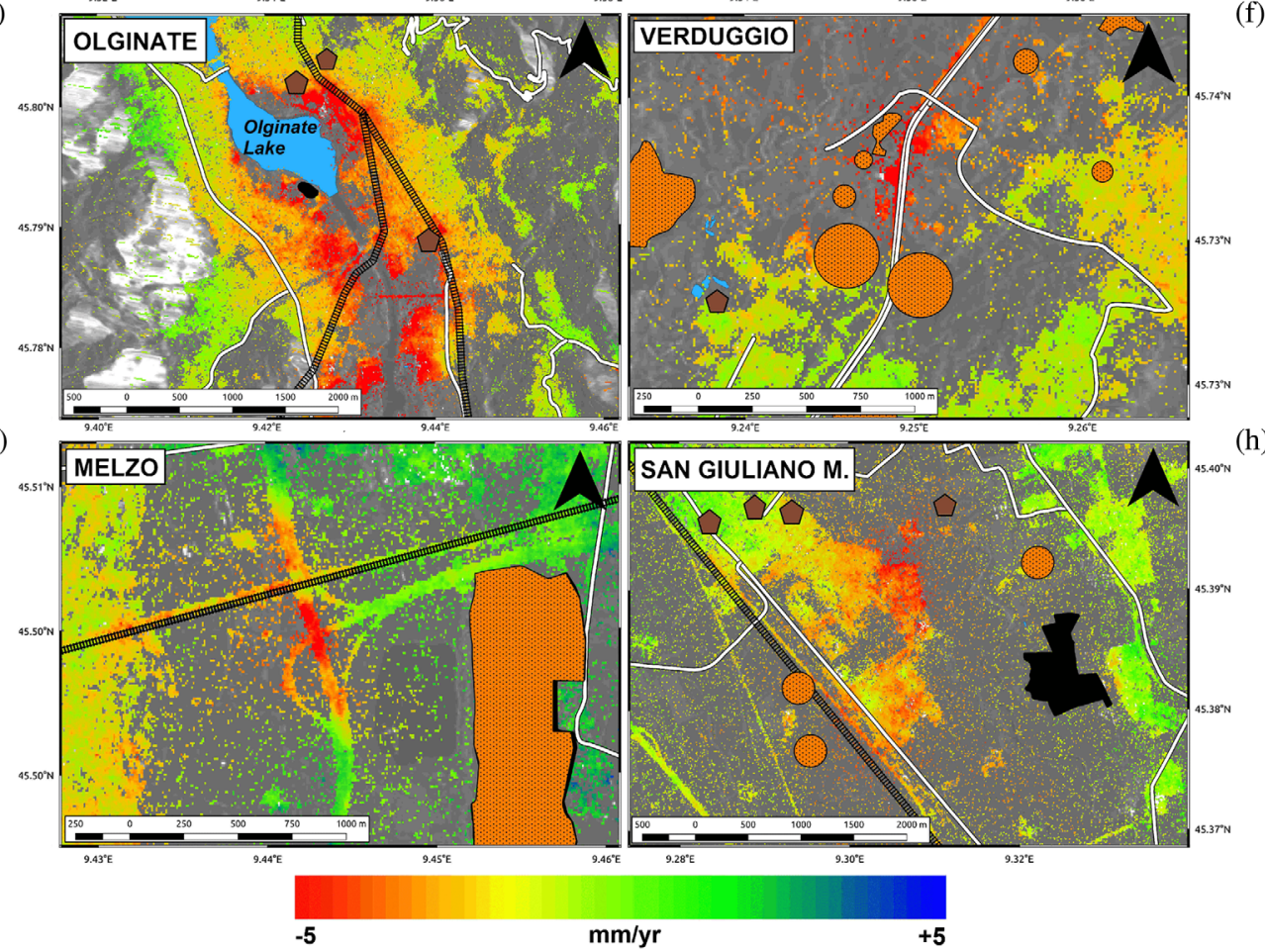

Fig. 2 Focus on the areas affected by subsidence. (a) Como, (b) "Erba," (c) "Oggiono," (d) "Valmadrera," (e) "Olginate," (f) "Verduggio," (g) "Melzo," and (h) "San Giuliano M." 
with deformation rates peaking at about 6 to $7 \mathrm{~mm} / \mathrm{year}$. They are mainly located in or near several industrial areas along the Como and Lecco provinces and in proximity of lakes, where the presence of soft sediments can lead and facilitate the subsidence process. This is the case of the subsidence phenomena detected in: (1) Como city, in the proximity of the eastern termination of Lake Como, hereinafter Como; (2) the industrial area south of Erba (CO) town, between Lake Pusiano and Lake Alserio, hereinafter Erba; (3) the industrial area south of Oggiono (LC) town and Lake Annone, hereinafter Oggiono; (4) the industrial area of Valmadrera (LC) town, between Lake Annone and the western termination of Lake Como, hereinafter Valmadrera; and (5) several industrial areas along the shores of Lake Garlate and Lake Olginate, hereinafter Olginate. Instead, the last subsidence phenomenon detected in the upper frame is located further south, in the Monza-Brianza province, along the SS36 highway, close the Veduggio con Colzano (MB) town, hereinafter Verduggio. On the other hand, in the second CSK frame, we observed two subsiding areas not so far from Milano city and with subsidence values slightly lower, peaking at about $5 \mathrm{~mm} /$ year. The first one is located along the A58 highway, east of Milano city, and close to Melzo (MI) town, hereinafter Melzo, whereas the second one surrounds the industrial areas of San Giuliano Milanese (MI), south of Milano city, hereinafter San Giuliano M. Avoiding the seasonal fluctuations, the time series show an almost linear trend for all the observed phenomena except for the Erba case study, where we observed an increase of the subsidence rate starting from May 2015. Melzo and San Giuliano M. case studies are characterized by a worse temporal sampling due to the fewer number of images available for the Milano dataset (Fig. 3). Such results are consistent with the slow and persistent in time, subsidence produced by the combination of several anthropogenic-induced factors as soil compaction, water pumping for industrial activities, and so on.

We explored several GNSS and leveling network based on previous studies and regional online services $^{22,39}$ to validate our results. Unfortunately, the observed subsidence phenomena are too local and only three GPS sites cover the InSAR frames. They are located in Como, where

(a)

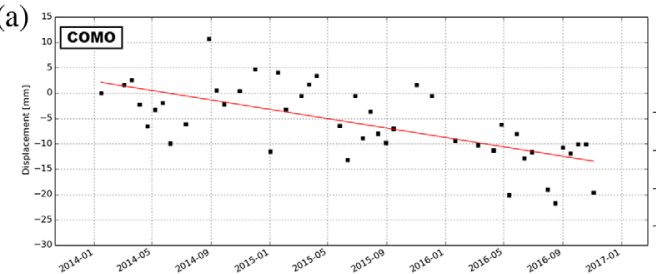

(c)

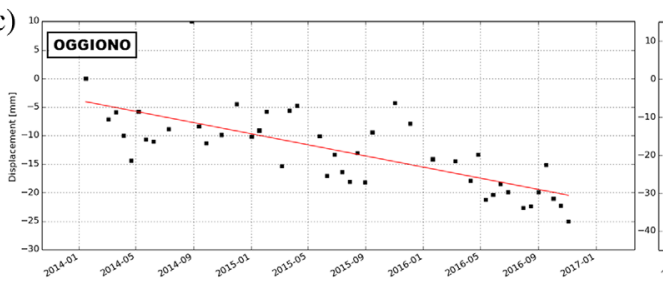

(e)
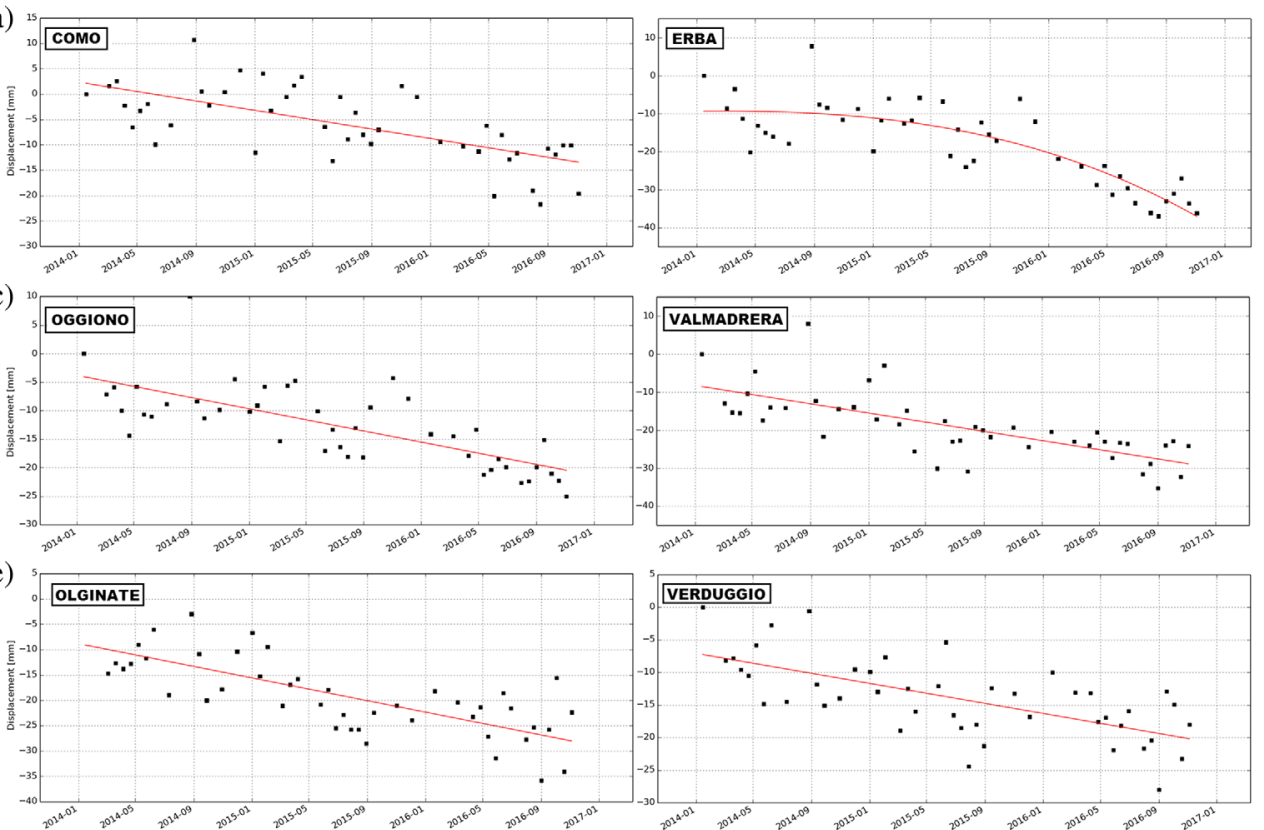

$(\mathrm{g})$
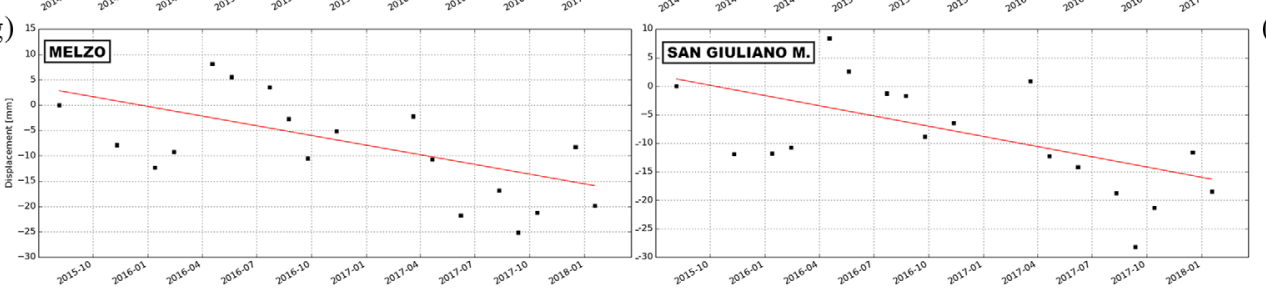

(b)

Fig. 3 Time series estimated along the areas highlighted in Fig. 2. (a) Como, (b) Erba, (c) Oggiono, (d) Valmadrera, (e) Olginate, (f) Verduggio, (g) Melzo, and (h) San Giuliano M. 

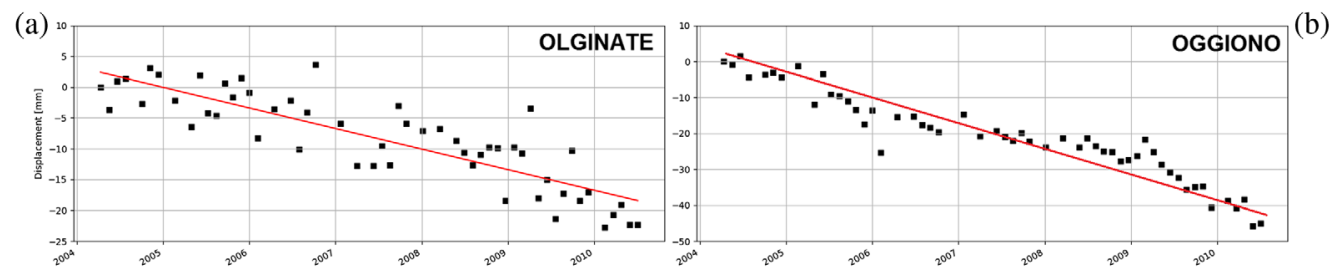

Fig. 4 (a) and (b) Point series retrieved by the PST project providing a cross-validation of the results.

the subsidence is already well known in the literature ${ }^{36}$ and in Lecco and Milano cities, where no deformation is observed. However, in order to carry out a sort of cross-validation, we exploited the ENVISAT InSAR data provided in the framework of the Italian project Piano Straordinario di Telerilevamento (PST). ${ }^{40}$ Such data are acquired in the time interval ranging from 2003 to 2010, i.e., several years before our CSK dataset but most of the deformation we observed show an almost linear behavior and we indeed found a general good agreement. In addition, it demonstrates how some of the detected phenomena are persistent over time (Fig. 4).

\section{Discussion}

The detected subsidence phenomena directly or indirectly involve several anthropogenic activities largely present between Como, Lecco, Monza-Brianza, and Milano provinces.

In the case of Erba, Oggiono, Olginate, and San Giuliano M., such phenomena are strictly connected to the soil compaction effects induced by the relatively recent industrial development in the peripheral areas as clearly observable in Fig. 5. Indeed, in these areas, there are nowadays many metallurgy industries, industries for the production of rolled steel strips, fastening systems, protective treatments for small mechanical parts and metal components, packaging industries, metallic carpentry industries, and commercial areas. In addition, in the immediate surrounding of the subsiding areas, many reclaimed sites, quarries, and landfills are present.
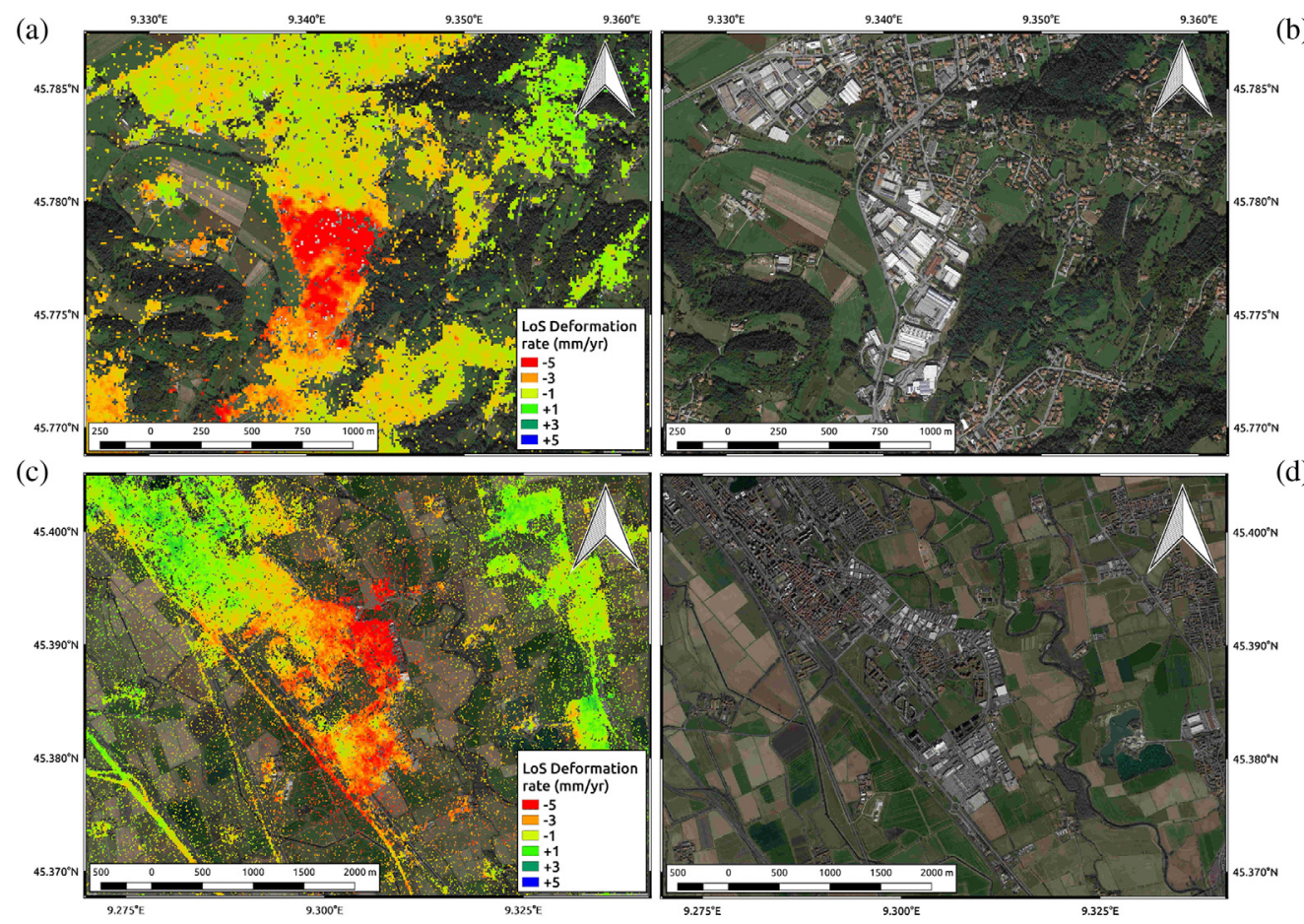

(d)

Fig. 5 (a) and (b) Oggiono and (c) and (d) San Giuliano M. case studies showing the influence of soil compaction effects in the observed subsidence because of the industrial expansion. 
In the case of Valmadrera, the observed subsidence is most likely due to the combination of soil compaction effects because of the industrial expansion and the presence of active and ceased quarries, which occupy an area of about $35,000 \mathrm{~m}^{2}$ along the Valmadrera town and surroundings. Particular care is required for Como case. The subsidence affecting the city is already known being due to natural phenomena mainly related to hydrogeological reasons. It is indeed located in a basin bordered by Lake Como and two tectonic lines, which delimit a narrow depression characterized by the large presence of alluvial soft sediments. ${ }^{36}$ Therefore, in this case, the anthropogenic contribution, consisting of many reclaimed sites thus involving water pumping activities, only amplify natural subsidence phenomena.

Concerning Melzo case, the subsidence observed along the A58-TEEM highway is probably ascribable to the proximity of the quarry exploited for the excavation of the materials used for the construction of the A58-TEEM highway itself. Such quarry caused a ground level lowering during the construction and has been ceased in 2016 and transformed in a naturalistic oasis for the birdwatching. ${ }^{41}$

Finally, Verduggio is in the proximity of the Lambro river and very close to several quarries for the extraction of clay then the combination of these two factors could have contributed to the detected deformation pattern.

All these subsiding areas are resting on the railway and/or road lines, which are then subject to the highlighted phenomena. Apart from Verduggio and Oggiono cases, the other sites are reached by several lines of the nested connection network of Lombardia region referred to as Rete Ferroviaria Italiana (RFI). Therefore, we mainly focus here on a railway line but any considerations can be easily extended to roads and/or highways.

A common railway infrastructure (RFI) consists of a track, which includes both flat bottom rails and sleepers, and track foundation, i.e., ballast, sub-ballast, a protective layer and subgrade overcoming the natural ground layer (see the lower part of Fig. 6). Therefore, the affordable traffic on a railway line is strictly connected to the quality of both track and track foundation layers. In this context, the role of the sleepers is very important since they support the rails and transfer dynamic loads into the ballast. The pressure loaded by a train passage can produce a settlement of the ballast further resulting in a slight settlement in the underneath layers including natural ground.

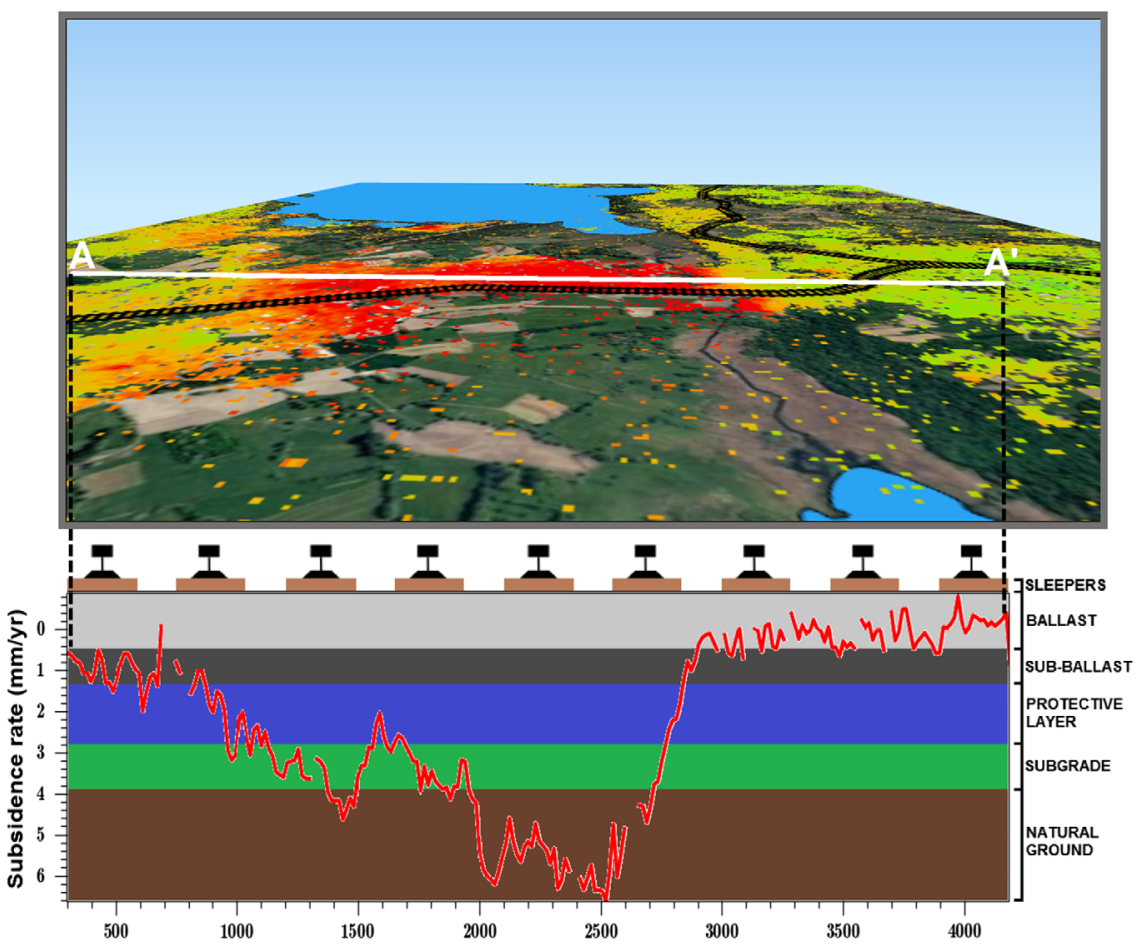

Fig. 6 Section of subsidence rate detected in the Erba case study indicated with AA' segment and superimposed on the section of railway line affected by the phenomenon. 
The subsidence induced by external/independent natural or anthropogenic-induced reasons along a railway line produces a further loading on each layer. In particular, as possible to note by Fig. 6, this leads to a load gradient in correspondence of the boundaries of the subsidence pattern, proportional to the difference in deformation rate between stable and subsiding areas. This means that flat bottom rails and the sleepers in the proximity of the subsidence boundaries will be affected by different displacement fields, i.e., about $6 \mathrm{~cm}$ of difference in 10 years for most of the analyzed cases. Such deformation gradient can be also seen as different downward pressures, which, in extreme cases, can cause the railway line to collapse. ${ }^{42}$

On the other hand, highways and roads are generally composed of three layers overlying the natural soil subgrade. A flexible surface layer of hot-mix asphalt, a base layer consisting of unstabilized aggregates, asphalt, bitumen, or cement and a subbase layer constructed from local aggregate material, while the top of the subgrade is often made stable with cement or lime.

The flexible surface layer is designed for transferring the stress from the top of the surface to the layers below. Indeed, one of the properties of the asphalt is to slightly deform when subjected to a stress field and then return to its original position when it is removed. Depending on the conditions of the layer, some small deformations can become permanent thus causing problems to wheels of the transiting cars. The life cycle of such layer is typically 20 to 30 years according to traffic loads, thickness, environmental conditions, and so on.

Then, as for a railway line, if the subgrade is subsiding, a further stress field need to be taken into account when designing a maintenance service of highways and roads especially considering parts crossed by bridges or viaducts.

\section{Conclusions}

We exploited X-band Cosmo-SkyMed InSAR data characterized by revisit time spanning from 16 to 35 days to investigate several localized deformation phenomena occurring in the Lombardia region (northern Italy) and affecting the nested railway and road network crossing the region.

Our InSAR-based analysis shows how the large presence of anthropogenic activities, mainly related to the industrial expansion of the area, is inducing some subsidence effects, which could be potentially dangerous for some parts of railway and road infrastructure.

Indeed, the detected deformations show an almost linear trend peaking at about 6 to $7 \mathrm{~mm} /$ year that does not seem to be going to any slowdown. If persistent and/or accelerating, these subsidence phenomena could become very significant in a few years and affect these infrastructures leading to a considerable deformation gradient along the boundaries of the detected displacement patterns. The ground subsidence is only one of the sources of stress affecting railways and/or highways, which include train speed, mass of a vehicle, cargo, vibrations due to surface imperfections, slight oscillation of vehicles along yaw, roll and pitch, and so on. ${ }^{43}$ However, discriminating between several causes and modeling future scenarios is not straightforward and is out of the scopes of this paper. Here, we want to point out the role and the possible exploitations of satellite remote sensing InSAR data for hazard assessment purposes in this application field especially considering the improved revisit time of 6 days obtained by Sentinel-1 missions of European Space Agency. Lombardia has already been interested by some train and road accidents and every day a million people move along the region. Therefore, in order to guarantee the safety of people, frequent monitoring of railway and road infrastructure including land conditions is strictly needed.

\section{Acknowledgments}

Project carried out using CSK ${ }^{\circledR}$ Products, C ASI (Italian Space Agency), delivered under an ASI license to use.

\section{References}

1. D. Massonet et al., "The displacement field of the Landers earthquake mapped by radar interferometry," Nature 364, 138-142 (1993). 
2. S. Stramondo et al., "Uncovering deformation processes from surface displacements," J. Geodyn. 102, 58-82 (2016).

3. M. Polcari et al., "Using multi-band InSAR data for detecting local deformation phenomena induced by the 2016-2017 Central Italy seismic sequence," Remote Sens. Environ. 201, 234-242 (2017).

4. A. Ferretti, C. Prati, and F. Rocca, "Permanent scatterers in SAR Interferometry," IEEE Trans. Geosci. Remote Sens. 39, 8-20 (2001).

5. P. Berardino et al., "A new algorithm for surface deformation monitoring based on small baseline differential SAR interferograms," IEEE Trans. Geosci. Remote Sens. 40, 2375-2383 (2002).

6. C. Werner et al., "Interferometric point target analysis for deformation mapping," in IEEE Int. Geosci. and Remote Sens. Symp., Vol. 7, pp. 4362-4364 (2003).

7. A. Ferretti et al., "A new algorithm for processing interferometric data-stacks: SqueeSAR," IEEE Trans. Geosci. Remote Sens. 49, 3460-3470 (2011).

8. F. Casu, M. Manzo, and R. Lanari, "A quantitative assessment of the SBAS algorithm performance for surface deformation retrieval from DInSAR data," Remote Sens. Environ. 102, 195-210 (2006).

9. S. Stramondo et al., "Subsidence induced by urbanisation in the city of Rome detected by advanced InSAR technique and geotechnical investigations," Remote Sens. Environ. 112, 3160-3172 (2008).

10. M. Polcari et al., "Subsidence detected by multi-pass differential SAR interferometry in the Cassino Plain (Central Italy): joint effect of geological and anthropogenic factors?" Remote Sens. 6, 9676-9690 (2014).

11. S. Ferlisi et al., "The use of DInSAR Data for the analysis of building damage induced by slow-moving landslides," Eng. Geol. Soc. Territory 2, 1835-1839 (2015).

12. D. Di Martire et al., "Comparison between differential SAR interferometry and ground measurements data in the displacement monitoring of the earth-dam of Conza della Campania (Italy)," Remote Sens. Environ. 148, 58-69 (2014).

13. P. Milillo et al., "Monitoring dam structural health from space: insights from novel InSAR techniques and multi-parametric modeling applied to the Pertusillo dam Basilicata, Italy," Int. J. Appl. Earth Obs. Geoinf. 52, 221-229 (2016).

14. G. Fornaro, D. Reale, and S. Verde, "Bridge thermal dilation monitoring with millimeter sensitivity via multidimensional SAR imaging," IEEE Geosci. Remote Sens. Lett. 10(4), 677-681 (2013).

15. A. Serrano-Juan et al., "Leveling vs. InSAR in urban underground construction monitoring: Pros and cons. Case of La Sagrera railway station (Barcelona, Spain)," Eng. Geol. 218, 1-11 (2017).

16. K.-Y. Eum, Y.-K. Park, and S.-S. Jeon, "Stability assessment of roadbed affected by ground subsidence adjacent to urban railways," Nat. Hazards Earth Syst. Sci. 18, 2261-2271 (2017).

17. D. Reale, G. Fornaro, and A. Pauciullo, "Extension of 4-D SAR imaging to the monitoring of thermally dilating scatterers," IEEE Trans. Geosci. Remote Sens. 51(12), 5296-5306 (2013).

18. A. Ferretti et al., "SAR analysis of building collapse by means of the permanent scatterers technique," in IEEE Geosci. Remote Sens. Symp., Vol. 7, pp. 3219-3221 (2000).

19. J. J. Sousa and L. Bastos, "Multi-temporal SAR interferometry reveals acceleration of bridge sinking before collapse," Nat. Hazards Earth Syst. Sci. 13, 659-667 (2013).

20. S. Stramondo et al., "Surface movements in Bologna (Po Plain - Italy) detected by multitemporal DInSAR," Remote Sens. Environ. 110, 304-316 (2007).

21. C. Meisina et al., "Ground deformation monitoring by using the permanent scatterers technique: the example of the Oltrepo Pavese (Lombardia, Italy)," Eng. Geol. 88, 240-259 (2006).

22. P. Baldi et al., "GPS-based monitoring of land subsidence in the Po Plain (Northern Italy)," Earth Planet. Sci. Lett. 288, 204-212 (2009).

23. S. Zerbini et al., "A combination of space and terrestrial geodetic techniques to monitor land subsidence: case study, the Southeastern Po Plain, Italy," J. Geophys. Res. Solid Earth 112(B5), B05401 (2007). 
24. G. Modoni et al., "Spatial analysis of land subsidence induced by groundwater withdrawal," Eng. Geol. 167, 59-71 (2013).

25. G. Marketos, R. Govers, and C. J. Spiers, "Ground motions induced by a producing hydrocarbon reservoir that is overlain by a viscoelastic rocksalt layer: a numerical model," Geophys. J. Int. 203, 198-212 (2015).

26. L. Jiang and H. Lin, "Integrated analysis of SAR interferometric and geological data for investigating long-term reclamation settlement of Chek Lap Kok Airport, Hong Kong," Eng. Geol. 110, 77-92 (2010).

27. E. Carminati, C. Doglioni, and D. Scrocca, "Alps vs. Apennines," in Geology of Italy, Special Volume of the Italian Geological Society for the IGC 32 Florence-2004 ed., Società Geologica Italiana, pp. 141-151 (2004).

28. P. Mosca et al., "New data for the kinematic interpretation of the Alps-Apennines junction (Northwestern Italy)," Int. J. Earth Sci. 99(4), 833-849 (2010).

29. G. Nangeroni, Il glaciale Quaternario nell'anfiteatro del Verbano e lungo $i$ rami del Lario, Fasc. III, Rendiconti Istituto Lombardo, Milano, Vol. LXXXVII, pp. 653-664 (1954).

30. A. Zanchi et al., "Neotectonic evidences along the Lombardian foothills of the Southern Alps," in Proc. Symp. South. Alps Quat. Geol., Geol. Insubr., Vol. 2, pp. 99-112 (1997).

31. F. Giardina et al., "The seismic potential of the Insubria Region (Southern Alps): insights from topographic and rheological modeling," Boll. Geofis. Teor. Appl. 45, 86-91 (2004).

32. D. Sciunnach and F. Tremolada, "The Lombardian Gonfolite Group in central Brianza (Como and Milano Provinces, Italy): calcareous nannofossils biostratigraphy and sedimentary record of neo-Alpine tectonics," Eclogae Geol. Helv. 97, 119-131 (2004).

33. G. Muttoni et al., "Onset on major Pleistocene glaciations in the Alps," Geology 31, 989-992 (2003).

34. S. Ivy-Ochs et al., "Timing of deglaciation on the Northern Alpine foreland (Switzerland)," Eclogae Geol. Helv. 97, 47-55 (2004).

35. L. Castelletti and G. Orombelli, "Una Nuova data 14C per La Storia Della Deglaciazione Del Bacino Del Lago di Como," Geogr. Fis. Din. Quat. 9, 56-58 (1986).

36. V. Comerci et al., "Land subsidence and Late Glacial environmental evolution of the Como urban area (Northern Italy)," Quat. Int. 173-174, 67-86 (2007).

37. R. Goldstein and C. Werner, "Radar interferogram filtering for geophysical applications," Geophys. Res. Lett. 25, 4035-4038 (1998).

38. M. Costantini, "A novel phase unwrapping method based on network programming," IEEE Trans. Geosci. Remote Sens. 36, 813-821 (1998).

39. Regione Piemonte-Regione Lombardia, "SPIN-GNSS: Servizio di Posizionamento Interregionale GNSS Piemonte-Lombardia," https://www.spingnss.it/spiderweb/frmIndex .aspx

40. Geoportale Nazionale, "Progetto piano straordinario di telerilevamento-Verifica e monitoraggio delle aree ad elevato rischio idrogeologico," http://www.pcn.minambiente.it/mattm/ progetto-piano-straordinario-di-telerilevamento/.

41. Tangenziale Esterna, "La cava teem di pozzuolo martesana (mi) diventa oasi naturalistica protetta," https://www.tangenziale.esterna.it/media/news-in-evidenza/la-cava-di-pozzuolomartesana-mi-diventa-oasi-protetta/ (29 September 2017).

42. H. Keqiang et al., "The effects of Karst collapse on the environments in North China," Environ. Geol. 52, 449-455 (2007).

43. L. Ferreira and M. Murray, "Modelling rail track deterioration and maintenance: current practices and future needs," Transport Rev. 17(3) 207-221 (1997).

Marco Polcari is a researcher at the Istituto Nazionale di Geofisica e Vulcanologia (INGV) in Rome, Italy. He is involved in Italian and international projects and is the author of several peerreviewed articles and conference papers. His main activity focuses on multitemporal SAR interferometry data processing and analysis for the study of surface displacement fields due to earthquakes, volcanoes inflation/deflation and urban subsidence; SAR and GPS data fusion for retrieving three-dimensional knowledge of a displacement field. 
Marco Moro is researcher at Istituto Nazionale di Geofisica e Vulcanologia (INGV). His skills include: (a) active tectonics studies to identify seismogenic sources and paleoseismology approach aimed at the characterization of the geometric and kinematic behaviour of the seismogenic structures; (b) analyses and interpretation of coseimic and interseismic deformations by InSAR techniques; (c) quaternary geology integrating the stratigraphic sequences to paleosurfaces for thegeological reconstruction of the quaternary evolution in basins sectors.

Vito Romaniello received his degree in physics from the Sapienza University of Rome in 2006, and his $\mathrm{PhD}$ in methods and technologies for environmental monitoring from the University of Basilicata in 2011. He is a postdoctoral researcher at the Istituto Nazionale di Geofisica e Vulcanologia, Rome, Italy. His current research interests include satellite change detection and atmospheric physics.

Salvatore Stramondo is the execute director of the National Earthquake Center at Istituto Nazionale di Geofisica e Vulcanologia (INGV). His main research activities are in SAR interferometry techniques and geophysical applications. He is author of 80 international papers. He has been coordinator of APhoRISM FP7 project and TERRAFIRMA Tectonic Theme GSE project. He has been chairman and cochairman at several international conferences. 